\title{
Disease-modifying factors in hereditary angioedema: an RNA expression-based screening
}

\author{
Alberto López-Lera ${ }^{1,2^{*}}$, Fátima Sánchez Cabo ${ }^{3}$, Sofía Garrido ${ }^{1}$, Ana Dopazo ${ }^{3}$ and Margarita López-Trascasa ${ }^{1,2}$
}

\begin{abstract}
Background: Hereditary Angioedema due to C1-Inhibitor deficiency (HAE types I and II) is a monogenic disease characterized by sudden, self-limited episodes of cutaneous and mucosal swelling due to local deregulation of vascular permeability. Despite its monogenic pattern of inheritance, HAE exhibits great clinical variability and low genotype/phenotype correlation among those affected, which ultimately hinders therapeutic approach and probably underlies yet unknown genetic and environmental factors.

Methods: We studied whole-genome RNA expression of PBMCs in three HAE type-l families (accounting for 40 individuals), 24 of which carry the same R472X mutation in the C1-Inhibitor gene and show large variability in terms of disease expression. Those included in this study were analyzed according to the presence of mutation and/or clinical symptoms.

Results: Instead of a single, common disease-associated expression pattern, we found different transcriptome signatures in two of the families studied. In one of them (referred to as DR family), symptoms correlate with the upregulation of 35 genes associated to the biological response to viral infections (including RSADs, OAS, MX and ISG pathway members) and immune response. In another pedigree ( $Q$ family), disease manifestation is linked to the upregulation of 43 genes with diverse functions, including transcription and protein folding. Moreover, symptoms-free members of the $Q$ pedigree display relatively higher expression of 394 genes with a wide diversity of functions.

Conclusion: We found no evidence for a common altered PBMC expression pattern linked to HAE symptoms in the three families analyzed. All the data considered, differential gene expression in PBMCs do not seem to play a significant role in the predisposition or protection against HAE in the basal -between crises- conditions analyzed. Although the RNA expression pattern associated to the response to viral infections observed in the DR family supports the idea of infectious diseases as a modifying factor for HAE severity, large-scale studies would be needed to statistically associate such expression pattern to the development of this rare disease.
\end{abstract}

Keywords: Disease-modifying factor, Expression microarray, Hereditary angioedema, Infection

\section{Introduction}

Hereditary Angioedema (HAE, OMIM\#106100) is a rare genetic condition characterised by the occurrence of severely incapacitating episodes of edema affecting mucosal and submucosal layers. Edema attacks in HAE develop spontaneously in any body location (face, limbs, genitals or upper respiratory and gastrointestinal tracts)

\footnotetext{
* Correspondence: alberlole@gmail.com

'Immunology Unit, Hospital Universitario La Paz and Hospital La Paz Research Institute (IdiPAZ), Madrid, Spain

${ }^{2}$ Centre for Biomedical Network Research on Rare Diseases (CIBERER), Instituto de Salud Carlos III (ISCIII), Madrid, Spain

Full list of author information is available at the end of the article
}

and can lead to life-threatening suffocation when there's involvement of the upper airways [1].

Inheritance of the disease is autosomal dominant due to deleterious mutations in the serpin (Serum protease inhibitor) C1-Inhibitor (C1-INH) (HAE types I and II) or gain-of-function mutations in the gene coding for the coagulation Factor XII (FXII) (HAE type III or oestrogen-related HAE) [2]. Both genetic alterations ultimately cause uncontrolled activation of the contact and kinin-forming cascades, as evidenced by the extensive activation of the factor XII-dependent pathways and bradykinin release observed in HAE patients' plasmas $[3,4]$. Bradykinin, through its interaction with its specific

\section{Biomed Central}

(c) 2013 López-Lera et al.; licensee BioMed Central Ltd. This is an Open Access article distributed under the terms of the Creative Commons Attribution License (http://creativecommons.org/licenses/by/2.0), which permits unrestricted use, distribution, and reproduction in any medium, provided the original work is properly cited. 
receptor on the endothelium surface, is considered the major mediator of edema in these patients [5].

Systematic genetic screening has been performed in HAE accounting for more than 200 mutations described to date in the CIINH locus (responsible for the majority of HAE cases). However, little or no genotype-phenotype correlation has been detected [6]. Patients with HAE carrying the same mutation exhibit large variability of symptoms' frequency and severity, even among siblings. Such variability hinders therapeutic assessment and probably underlies yet unknown genetic and environmental factors.

A potential source of clinical variation comes from the poorly studied role of adaptive immunity in HAE. Although some reports exist indicating abnormal distribution of $\mathrm{T}$ lymphocyte surface receptors, reduced Langerhans cell numbers and abnormal $\mathrm{T}$ - and $\mathrm{B}$-cell counts in HAE patients $[7,8]$, little is known about how adaptive immunity function and variation may modify the clinical expression of the disease. More precisely, how innate and adaptive immunity crosstalk in dealing with infection is of particular interest, as viral and bacterial infections are known to induce hives and edema under certain pathological situations.

In the present report, we intended to study the contribution of peripheral blood mononuclear cells (PBMCs) to the clinical expression of HAE. For this purpose, the RNA expression profile of PBMCs from 3 large HAE type I families was analyzed according to the presence of mutation in the C1INH locus (R472X) and the existence or frequency of clinical symptoms of angioedema. Our results did not evidence common alterations in the expression pattern of PBMCs in association to the frequency and severity of disease manifestations in the 3 families. Instead, different expression profiles associated to disease manifestation in each family, suggesting that the PBMC compartment does not make a significant contribution to HAE pathology in basal, non-inflammatory conditions.

\section{Materials and methods}

\section{Ethics statement}

Biological sampling of human PBMCs was carried out upon informed consent from the participants. The ethical committee of Hospital La Paz gave approval to these studies.

\section{Patients and samples}

HAE families were selected for these experiments on the basis of two criteria: (i) the presence of a common mutation in the C1INH locus segregating in the family and (ii) the existence of a wide variability of symptoms' frequency among the affected individuals. Three non related families carrying the R472X mutation were chosen: family AR
(16 members), family DR (9 members) and family Q (15 members) (Table 1). In each family, the index case was assigned number 0 (e.g. AR0), while the remaining family members received correlative numbers depending on their respective consanguinity (eg. AR1, AR2...). Additionally, those family members not carrying the R472X mutation were included in the study as healthy controls.

For the statistical analyses, patients were clustered in clinical categories according to their disease severity index, as previously described [6] (Table 1).

In the DR family and based on the available experimental data dealing with the extent of androgen effects on C1-INH synthesis [9], treatment was suspended two weeks before blood sampling upon consent from their physicians. As demonstrated by Gelfand and colleagues, the effect of androgen treatment, as measured by the increase in C1-INH and C4 serum levels, is maximal by one to two weeks after the onset of the treatment but decreases rapidly once it is stopped. For this reason, we set two weeks after treatment removal as a convenient lapse of time for sample collection. None of the patients referred angioedema symptoms or other pathological conditions at the time of sampling.

For validation purposes and in order to investigate the permanence of the detected RNA expression patterns, duplicated samples (first extraction at the time of the microarray experiment and a second one, 10 months later) were extracted and handled as recommended by the manufacturer prior to processing. $2.5 \mathrm{~mL}$ of whole blood were collected into each PAXgene ${ }^{\text {Tx }}$ Blood RNA Tube (PreAnalytix ${ }^{\circ} \mathrm{GmbH}$, Switzerland) using standard methods. RNA was isolated from blood samples using the PAXgene ${ }^{\text {tm }}$ Blood RNA Kit (PreAnalytix). The quality and integrity of RNA were assessed both by agarose gel electrophoresis and bioanalyzer methods. Absorbances at 260, 230 and $280 \mathrm{~nm}$ were measured and the A260/ 280 and A260/230 ratios were considered adequate. Additionally, EDTA-plasma samples were separated and stored at $-80^{\circ} \mathrm{C}$ until used.

\section{Labeling of RNA and microarray hybridization}

One-Color Microarray-Based Gene Expression Analysis Protocol (Agilent Technologies ${ }^{\circ}$, Palo Alto, CA, USA) was used to amplify and label RNA. Briefly, $800 \mathrm{ng}$ of total RNA from patients and controls, were reverse transcribed using T7 promoter primer and the Moloney murine leukemia virus (MMLV) reverse transcriptase (RT). cDNA was then converted to anti-sense RNA (aRNA) by using T7 RNA polymerase which amplifies target material simultaneously incorporating cyanine 3 (Cy3)-labeled CTP. Samples were hybridized to a Whole Human Genome Microarray $^{\text {Tim }} 4 x 44 \mathrm{~K}$ (G4845A, Agilent Technologies $\left.{ }^{\circ}\right) .1 .65$ micrograms of Cy3-labeled aRNA were hybridized for 17 hours at $65^{\circ} \mathrm{C}$ in an Agilent hybridization oven 
Table 1 Cohort descrip0074ion

\begin{tabular}{|c|c|c|c|c|c|c|c|c|c|}
\hline Family code & Gender & Age & Arg472Stop & $\begin{array}{l}{[\mathrm{C} 1-\mathrm{INH}]} \\
(\mathrm{mg} / \mathrm{dL})\end{array}$ & $\begin{array}{c}\text { C1-INH activity } \\
\text { (\% of NHP) }\end{array}$ & Symptoms & $\begin{array}{c}\text { Treatment } \\
\text { needed }\end{array}$ & $\begin{array}{c}\text { Severity } \\
\text { score }\end{array}$ & $\begin{array}{c}\text { Severity } \\
\text { degree }\end{array}$ \\
\hline \multicolumn{10}{|l|}{ Family AR } \\
\hline ARO & $\mathrm{F}$ & 37 & Yes & 8.80 & 31.98 & Yes & Androgens & 43 & Severe \\
\hline AR2 & $\mathrm{F}$ & 64 & Yes & 6.84 & 25.11 & Yes & Androgens & 48 & Severe \\
\hline AR3 & M & 26 & Yes & 4.53 & 13.36 & Yes & Androgens & 48 & Severe \\
\hline AR4 & M & 60 & Yes & 7.51 & 25.06 & Yes & Androgens & 48 & Severe \\
\hline AR5 & $\mathrm{F}$ & 27 & Yes & $<2.98$ & 21.46 & Yes & No & 24 & Moderate \\
\hline AR7 & $\mathrm{F}$ & 60 & Yes & 5.81 & 18.21 & Yes & Androgens & 43 & Severe \\
\hline AR8 & $\mathrm{F}$ & 26 & Yes & 3.56 & 10.84 & Yes & Androgens & 49 & Severe \\
\hline AR9 & $\mathrm{F}$ & 40 & Yes & 3.79 & 18.28 & Yes & No & 12 & Mild \\
\hline AR10 & M & 53 & Yes & 7.05 & 34.24 & No & No & 0 & Asymptomatic \\
\hline AR11 & M & 30 & No & 22.30 & $>100$ & - & - & - & - \\
\hline AR12 & $\mathrm{F}$ & 56 & No & 19.90 & $>100$ & - & - & - & - \\
\hline AR13 & $F$ & 44 & No & 25.30 & $>100$ & - & - & - & - \\
\hline AR14 & M & 51 & No & 23.90 & $>100$ & - & - & - & - \\
\hline AR15 & M & 52 & No & 18.70 & $>100$ & - & - & - & - \\
\hline AR16 & M & 45 & No & 25.80 & $>100$ & - & - & - & - \\
\hline AR17 & M & 47 & No & 25.30 & $>100$ & - & - & - & - \\
\hline \multicolumn{10}{|l|}{ Family DR } \\
\hline DRO & $\mathrm{F}$ & 52 & Yes & 3.65 & 24.8 & Yes & No & 17 & Mild \\
\hline DR1 & M & 81 & Yes & 5.72 & 22.41 & No & ACE-i & 0 & Asymptomatic \\
\hline DR3 & M & 32 & Yes & 5.07 & 26.70 & No & No & 0 & Asymptomatic \\
\hline DR4 & M & 26 & Yes & 5.49 & 20.47 & No & No & 0 & Asymptomatic \\
\hline DR5 & $\mathrm{F}$ & 17 & No & 24.30 & $>100$ & - & - & - & - \\
\hline DR6 & M & 75 & No & 21.50 & $>100$ & - & - & - & - \\
\hline DR7 & M & 41 & No & 24.90 & $>100$ & - & - & - & - \\
\hline DR8 & $\mathrm{F}$ & 39 & No & 18.00 & $>100$ & - & - & - & - \\
\hline DR9 & $\mathrm{F}$ & 37 & No & 20.30 & $>100$ & - & - & - & - \\
\hline
\end{tabular}

\section{Family $Q$}

\begin{tabular}{|c|c|c|c|c|c|c|c|c|c|}
\hline Q0 & $\mathrm{M}$ & 82 & Yes & 4.11 & 10.68 & Yes & Androgens & 48 & Severe \\
\hline Q3 & $F$ & 86 & Yes & 7.61 & 25.44 & No & No & 0 & Asymptomatic \\
\hline Q4 & $F$ & 57 & Yes & 11.80 & 40.63 & Yes & Androgens & 26 & Moderate \\
\hline Q6 & $F$ & 36 & Yes & 4.64 & 16.42 & Yes & Androgens & 49 & Severe \\
\hline Q7 & $F$ & 50 & Yes & $<2.98$ & 9.76 & Yes & No & 25 & Moderate \\
\hline Q8 & $F$ & 48 & Yes & 5.88 & 16.26 & Yes & No & 28 & Moderate \\
\hline Q9 & $F$ & 24 & Yes & 3.27 & 14.92 & Yes & No & 48 & Severe \\
\hline Q10 & $F$ & 71 & Yes & 6.28 & 17.23 & No & - & 0 & Asymptomatic \\
\hline Q11 & $M$ & 56 & No & 21.30 & $>100$ & - & - & - & - \\
\hline Q12 & $F$ & 44 & No & 16.05 & 86.99 & - & - & - & - \\
\hline Q13 & $M$ & 38 & No & 26.40 & $>100$ & - & - & - & - \\
\hline Q14 & $F$ & 47 & No & 20.30 & $>100$ & - & - & - & - \\
\hline Q15 & $F$ & 75 & Yes & 6.34 & 18.00 & Yes & Androgens & 25 & Moderate \\
\hline Q16 & $F$ & 40 & Yes & 4.78 & 26.70 & Yes & Androgens & 27 & Moderate \\
\hline Q17 & $M$ & 45 & Yes & & & Yes & Androgens & 25 & Moderate \\
\hline
\end{tabular}

Three HAE families were included in the microarray study: AR (16 members), DR (9 members) and Q (15 members). Treatment received by the patient and the associated severity score at the time of sampling are shown. F: female; M: male; NHP: Normal Human Plasma; ACE-i: Angiotensin Converting Enzyme- inhibitors; *: Not determined. 
(G2545A, Agilent Technologies) set to $10 \mathrm{rpm}$ in a final concentration of 1x GEx Hybridization Buffer HI-RPM (Agilent Technologies). Arrays were washed and dried out according to manufacturer's instructions (One-Color Microarray-Based Gene Expression Analysis, Agilent Technologies), and scanned at $5 \mathrm{~mm}$ resolution on an Agilent DNA Microarray Scanner ${ }^{\mathrm{TM}}$ (G2565BA, Agilent Technologies $^{\odot}$ ) using the default settings for $4 \mathrm{x} 44 \mathrm{k}$ format one-color arrays. Images provided by the scanner were analyzed using Feature Extraction software v10.1.1.1 $1^{\mathrm{TM}}$ (Agilent Technologies ${ }^{\circledR}$ ).

\section{Preprocessing and data analysis}

Raw signals were thresholded to 1 and quantiles normalization [10] was performed using GeneSpring ${ }^{\mathrm{Ts}}$ software. Data were considered in the log2 scale. Default flags were considered as absent, except saturated spots that were flagged as marginal.

From the initial 34183 probes present in the chip, 20441 remained after applying the by-expression, by-flag and by-error data filtering. Based on statistical outliers criteria implemented in the Bioconductor package ArrayQualityMetrics $^{\mathrm{TM}}$, four samples showing excessive variance among replicates (AR5, AR16, Q0 and Q4) were removed for further analysis. Two different statistical analyses were performed using the Limma ${ }^{\mathrm{Tm}}$ package from Bioconductor: (i) patients with mutation versus patients without mutation, using the families as controlling variable (random factor) and (ii) symptomatic versus asymptomatic patients carrying mutation in each family.

\section{Analysis of microarray results}

The web-based pathways analysis tool IPA (Ingenuity Systems ${ }^{\oplus}$, www.ingenuity.com) was used to identify biological pathways affecting the development of edema in HAE. Gene expression was considered as significantly upregulated when Fold Change (FC) was above 2. The differentially expressed genes among symptomatic and asymptomatic HAE patients were classified with gene ontology (GO) analysis using the Database for Annotation, Visualization and Integrated Discovery (DAVID) v6.7. In this process, Fisher exact $p$ values are used to measure the gene-enrichment in annotation terms while Benjamini scores provide an estimation of the False Discovery Rate (FDR). FDR is defined as the expected proportion of false positives among the declared significant results. Clustering results were considered significant only when both the $p$ value and FDR statistics were below 0.05 .

\section{Real time PCR}

TaqMan custom assay primers and probes (Roche Diagnostics ${ }^{\oplus}$, Barcelona, Spain) were designed by using the manufacturer's Universal Probe Library Assay Design Center. In all cases, the RNA integrity and the specificity of RT-PCR amplified products were analyzed for by agarose-gel electrophoresis prior to quantification. Analysis of the results was performed with the standard curve method and using the GAPDH and $\beta$-actin genes for normalization. Equal amplification efficiencies were assessed for target and reference genes.

Total RNA (500 ng) from patients and controls was amplified using the SuperScript First Strand Synthesis System $^{\text {TM }}$ with random hexameres (Invitrogen ${ }^{\circ}$, Carlsbad, CA, USA). Real Time PCR was performed according to the manufacturer's protocols in a LightCycler ${ }^{\bullet}$ Carousel-based System. All samples were loaded by duplicate and negative controls (no-template) were included in every experiment. RT-PCR experiments were conducted on RNA samples isolated from two independent blood extractions. The primers used for RT-qPCR validation were designed at Universal Probe Library Assay Design Centre (http:// www.roche-applied-science.com/sis/rtpcr/upl/index.jsp? $\mathrm{id}=\mathrm{UP030000)}$. The primers sequences were: RIG-I (NM_014314.3) 5'TGGACCCTACCTACATCCTGA3' (F) and 5'GGCCCTTGTTGTTTTTCTCA3' (R);IFIT1 (NM_001548.3) 5'AGAACGGCTGCCTAATTTACAG3' (F) and 5'GCTCCAGACTATCCTTGACCTG3' (R);ISG15 (NM_005101.3) 5'GCGAACTCATCTTTGCCAGT3' (F) and 5'AGCATCTTCACCGTCAGGTC3' (R);OAS3 (NM_006187.2).

\section{Protein analysis in serum}

In order to study the cytokines signature of the patients' sera, selected protein markers were quantified using an on-demand magnetic-bead-based multiplex immunoassay from Bio-Rad (Bio-Plex Cytokine Group I 10-plex Assay; Bio-Rad ${ }^{\oplus}$, Hercules, CA, USA). The kit included beads, probes and reagents for the quantification of IL-2, IL-4, IL-5, IL-6, IL-8, IL-10, IL-12p70, IL-17a, IFN- $\gamma$ and TNF- $\alpha$ in serum or plasma.

\section{Results}

\section{Microarray results}

For the evaluation of the results, a threshold of Fold Change (FC):2 was used in order to provide a conservative foundation for further interpretations. Overall analysis of the microarray outcome did not evidence alterations in the expression pattern of a single pathway in the HAE symptomatic individuals from our cohort. Instead, it suggests the involvement of different pathways in two of the families studied. Age and sex showed no major association to clinical frequency and severity in the series.

The experimental population was stratified in subgroups according to the "severity index" criteria and analyzed accordingly. Only those comparisons reaching significance are shown. 


\section{Genes showing altered expression patterns in HAE symptomatic patients}

Genes exhibiting altered patterns of expression in each family are enlisted in Table 2.

\section{Family $D R$}

In the DR family, DR0 is a 52-year-old woman suffering from 1-3 cutaneous edema episodes per year in the absence of treatment. Her mutation-carrying relatives DR1, DR3, DR4 (three males of ages ranging from 26 to 81) have been free of symptoms for the last two years or longer. None of the three males is receiving HAE-related treatments and, what is more, DR1 has remained asymptomatic even during ACE-i treatment, which is a potent edema-precipitating drug in HAE patients [11].

Analysis of the transcriptome in the DR family revealed significant upregulation $(\mathrm{FC}>2$; adjpvalue $<0.05)$ of 35 genes in DR0, 27 of which are upregulated above 4FC (Table 2). Top hits in this patient are: RSAD2, IFIT1, IFI44L, CMPK2, ISG15, HERC5, OAS3 and IFI44. Validation of the results was performed by RT-qPCR quantification of ISG15, IFIT1, OAS3 and RIG-I in DR family members (correlation coefficient $\mathrm{R}^{2}: 0.8327$ ) (Figure 1). Among the remaining upregulated genes in DR0, the RNA helicase RIG-I (FC: 3,68) is relevant because it is considered a very specific signature of the presence of virus-derived RNA species into host cells $[12,13]$. Gene Ontology (GO) analysis confirmed enrichment of GO terms related to the biological response to virus (pvalue:7. $3 \times 10^{-7}$; FDR:1.2 $\times 10^{-4}$ ), RNA binding (pvalue: $2.0 \times 10^{-4} ; \quad$ FDR:1.5 $\times 10^{-2}$ ) and endoplasmic reticulum-associated catabolic process (pvalue: $3.8 \times 10^{-2}$; FDR:4. $\times 10^{-2}$ ). We did not identify transcripts significantly downregulated above the imposed threshold of -2FC in DR0 as compared to the remaining DR family members. The complete raw data are accessible as Additional file 1: Table S1, Additional file 2: Table S2, Additional file 3: Table S3).

We also measured cytokines' levels in the sera of DR family members in two independent samples obtained in a 10 months interval. In both measurements, DR0 exhibited significantly higher expression of IL4, IL5 and IL8 as compared to healthy controls and symptoms-free relatives (with or without mutation in the C1INH locus) (Figure 2). This cytokine expression pattern suggests a Th2 response and, therefore, the involvement of humoral immunity. IL4 stimulates B cells and induces immunoglobulin class switching to IgE. It also has a role in chronic inflammation and wound repair by modulating the activity of macrophage subpopulations. IL5 is produced by Th2 and mast cells. It is involved in B cell growth stimulation, immunoglobulin production and activation of eosinophils. As such, its overproduction has been associated to allergic disease and asthma [14]. IL8 is a key mediator of inflammation. It is produced mainly by macrophages, endothelial and epithelial cells, although it can be secreted by a variety of cells upon TLR stimulation. It promotes chemotaxis in neutrophils and maintains proinflammatory conditions by inducing further increase in oxidant stress mediators, thus being implicated in chronic inflammatory diseases [15].

Whether or not this cytokine profile is directly related to the gene expression pattern observed in the microarray of the patient is beyond the score of this paper. But taking under consideration the outcome of the microarray in DR0, the fact that similar results were obtained in the quantification of serum cytokines in two time-elapsed samples, and the absence of infectious manifestations in the patient, the picture is suggestive of a chronic, asymptomatic process. By analyzing the patient's serum antibodies, we discarded a putative Influenza infection as causative of the gene expression pattern observed in DR0 (data not shown).

All considered, the rationale underlying these results may be that, in the DR family, long-lasting, chronic viral infections are a major triggering factor of angioedema. Furthermore, it is feasible that genetic variation in one or several genes involved in the immune response against viruses and immune system regulation could influence both the course of infection and the development of HAE symptoms.

On the other hand, the three asymptomatic males in the DR family exhibit upregulation of 32 transcripts related to diverse biological functions that do not constitute significant functional clusters, but share functional links among them. That is the case of OLIG1 and OLIG2 transcription factors, which are expressed mainly during central nervous system development [16], and RAVER and PTBP1, both implicated in binding to polypyrimidine tract sequences and regulating the expression of alternative splicing forms [17].

\section{Family $Q$}

Two members of this family carrying the R472X substitution in C1-INH (Q3 and Q10) are asymptomatic and do not require specific treatment for HAE. Examination of the transcriptome in the asymptomatic individuals in this family reveals relative upregulation of 394 transcripts whose clustering, according to the transcripts' associated biological processes, renders only one significant group of 29 genes with "Transcriptional activation activity" (pvalue: $5.7 \times 10^{-4}$; FDR: $7.1 \times 10^{-2}$ ) (Table 2). Within this set of genes, IL17F is upregulated above 4fold, which could be related to the induction of proinflammatory responses; however, it could not be measured in the patient's plasma.

Another consistent set of genes upregulated in asymptomatic mutation carriers from this family which is associated to "Structural molecule activity" is composed 
Table 2 Microarray results

\begin{tabular}{|c|c|c|c|c|}
\hline \multirow[t]{2}{*}{ Family DR } & \multicolumn{4}{|c|}{ Genes upregulated IH the symptomatic palielit DRO } \\
\hline & Gene & FC & Adjpvalue & Description \\
\hline \multirow{16}{*}{$\begin{array}{l}\text { Type I Interferon signaling pathway } \\
\text { and /or Response to virus }\end{array}$} & ISG15 & 11.87 & 0.0012 & ISG15 ubiquitin-likemodifier(ISG15). [NM_005101] \\
\hline & HERC5 & 11.63 & 0.0094 & hect domain and RID 5 (HERC5). [NM_U 16323] \\
\hline & OAS3 & 11.00 & 0,0094 & $\begin{array}{l}\text { 2'-5'-oligoadenylate synthetase 3, I00kDa (OAS3) } \\
\text { [NM_006187] }\end{array}$ \\
\hline & IFI44 & 10.70 & 0,0318 & interferon-induced protein 44 (IFI44). [NM_006417] \\
\hline & 1F1141. & 17.03 & 0.0267 & $\begin{array}{l}\text { interferon-induced protein 44-like (IFI44L), mRNA } \\
\text { [NM_006820] }\end{array}$ \\
\hline & MXI & 9.25 & 0,0241 & myxovirus resistance 1 (MX1), [NM_002462] \\
\hline & $1 F 16$ & 8.57 & U.U1M & $\begin{array}{l}\text { Interferon, alpha-inducible protein } 6 \text { (IFI6) variant } 3 \\
\text { [NM_022873] }\end{array}$ \\
\hline & IFIT3 & 861 & 00588 & $\begin{array}{l}\text { interfernn-indnced protein with tetratricnpeptide } \\
\text { repeals } 3 \text { (IFIT3). [NM_00 1549] }\end{array}$ \\
\hline & IFIT2 & 7.26 & 0,0096 & $\begin{array}{l}\text { interferon-induced protein with tetratricopeptide } \\
\text { repeats } 2 \text { (IFIT2), [NM_00 1547] }\end{array}$ \\
\hline & OASL & 7.21 & 0,0485 & $\begin{array}{l}\text { 2'-5'-oligoadenylate synthetase-like (OA.SL), variant 1, } \\
\text { [NM 0037331] }\end{array}$ \\
\hline & USP18 & 6.23 & 0,0080 & $\begin{array}{l}\text { ubquitin specific peptidase } 18 \text { (USP18), varient 1, } \\
\text { [NM_017414] }\end{array}$ \\
\hline & OAS2 & 5.89 & 0,050 & $\begin{array}{l}\text { 2'-5'-oligoadenylate synthetase 269/71/kDA (OAS2), } \\
\text { variant 3, [NM_001032731] }\end{array}$ \\
\hline & XAF1 & 4.96 & 0,0116 & XIAP associated factor 1 (XAF1), variant 1, [NM 017523] \\
\hline & RSAD2 & 29.85 & 0,0128 & $\begin{array}{l}\text { radical S-alenosyl methionine domain containing } 2 \\
\text { (RSAD2 [NM_OS0657] }\end{array}$ \\
\hline & IFIT1 & 20.25 & 0,0241 & $\begin{array}{l}\text { interferon-induced protein with tetratricopeptide } \\
\text { repeats } 1 \text { (IFIT1), [NM 001548] }\end{array}$ \\
\hline & IFIT35 & 2.71 & 0.050 & interferon-induced protein 35 (IF135) [NM 005533] \\
\hline \multirow[t]{2}{*}{ Endoplasmic reticulum unfolded protein response } & HSP90AB1 & 7.84 & $1,35 \mathrm{E}-06$ & $\begin{array}{l}\text { heat shock protein 90kDa alpha, class B member } 1 \\
\text { (HSP9OAB 1) [NM 007355] }\end{array}$ \\
\hline & DERL3 & 9.92 & 0,0116 & $\begin{array}{l}\text { Derl-lilce domain family, member } 3 \text { (DERL3), variant 3, } \\
\text { rnRNA [NM_198440] }\end{array}$ \\
\hline & RIG-1 & 3.68 & 0,0496 & retinoic acid inducible gene I (RIG-I) [NM_014314] \\
\hline & DHX58 & 3.23 & $2,44 \mathrm{E}-05$ & $\begin{array}{l}\text { DEXH (ASp-Glu-X-His) box polypeptide } 58 \text { (DHX58), } \\
\text { [NM_024119] }\end{array}$ \\
\hline & ZBP1 & 3.36 & 0,0012 & Z-DNA binding protein 1 (ZBP1), variant 1, [NM 030776] \\
\hline & EIF2AK2 & 4.79 & 0,0182 & $\begin{array}{l}\text { eukaryotic translation initiation factor 2-alpha kinase } 2 \\
\text { (EIF2AK2), [NM_002759] }\end{array}$ \\
\hline & PARP12 & 2.50 & 0,050 & $\begin{array}{l}\text { poly (ADP-ribose Polyrnerace family. member } 12 \text { (PARP12). } \\
\text { [NM_022750] }\end{array}$ \\
\hline \multirow{8}{*}{ Other } & CMPK2 & 14.02 & 0,0036 & $\begin{array}{l}\text { cytidine monophosphate kinace 2. mitochondrial } \\
\text { (CMPK2L [NM_207315] }\end{array}$ \\
\hline & LAMP3 & 8.28 & 0,0128 & $\begin{array}{l}\text { lysosornal-acsociated membrane protem } 3 \text { (LAMP3), } \\
\text { [NM_0 14398] }\end{array}$ \\
\hline & SPATS2T & 5.77 & 0,0080 & $\begin{array}{l}\text { spermatogenisis associated serine-rich 2-like (SPAT2L) } \\
\text { [NM_001100422] }\end{array}$ \\
\hline & USP4I & 4.53 & 0,0182 & $\begin{array}{l}\text { partial mRNA for ubiquitin-specific protease } 41 \\
\text { (USP41 gene). [AJ586979] }\end{array}$ \\
\hline & PROM2 & 5.73 & 0,0406 & prominin 2 (PROM2) variant 3, [NM_144707] \\
\hline & DNHD1 & 5.58 & 0,0241 & $\begin{array}{l}\text { dynein heavy chain domain } 1 \text { (DNHD1), variant 2, } \\
\text { [NM 173589] }\end{array}$ \\
\hline & LOC64494 & 5.09 & 0,0249 & cDNA FLJ455O9 fis, clone BRTHA2020811. [AK127417] \\
\hline & IFIT5 & 4.86 & 0.0128 & $\begin{array}{l}\text { interferon-induced protein with tetratricopeptide repeats } \\
5 \text { (IFIT5), [NMO 12420] }\end{array}$ \\
\hline
\end{tabular}


Table 2 Microarray results (Continued)

\begin{tabular}{cccl} 
LY6E & 4.44 & 0,0101 & $\begin{array}{l}\text { lymphocyte antigen 6 complex. locus E çLY6E), variant I, } \\
\text { [NM U02.s4b] }\end{array}$ \\
\hline INPP5F & 3.48 & 0,0122 & $\begin{array}{l}\text { inosito1 po1yphnphale-S-phnsphalaceF(fNPPSF) variant 1 } \\
\text { [N1 (it 014917] }\end{array}$ \\
\hline TTC21A & 3.14 & 0,0462 & $\begin{array}{l}\text { tetratricopeptide repeat domain 21A (TTC21A), variant 2, } \\
\text { [NM 145755] }\end{array}$ \\
\hline FGD2 & 2.71 & 0,0560 & $\begin{array}{l}\text { FYVE, RhoGEF and PH domain containing 2 (FDG2) } \\
\text { [NM_173558] }\end{array}$
\end{tabular}

Family Q

Genes upregulated in asymptomatic versus severely affected individuals

\begin{tabular}{|c|c|c|c|c|}
\hline Biological process & Gene & FC & Adjpvalue & Description \\
\hline & SMAD5 & 5.35 & 0.0140 & SMAD family member 5 (NM_001001419) \\
\hline & KLF15 & 3.58 & 0.0142 & Kruppel-like factor 15 (006814) \\
\hline & ATXN7 & 10.26 & 0.0144 & ataxin 7 (NM_001128149) \\
\hline & UTF1 & 4.59 & 0.0158 & $\begin{array}{l}\text { undifferentiated embronic cell transcription factor } \\
\text { (NM_003577) }\end{array}$ \\
\hline & $\mathrm{ALX} 4$ & 4.00 & 0.0179 & ALX homeobox 4 (ENST00000329255) \\
\hline & MAFA & 3.65 & 0.0182 & $\begin{array}{l}\text { v-maf musculoaponeuroticfibrosarcoma oncogene } \\
\text { homolog A(NM_201589) }\end{array}$ \\
\hline & RARA & 17.22 & 0.0219 & retinoic acid receptor, alpha (NM_001024809) \\
\hline & Tead1 & 5.20 & 0.0220 & TEA domain family member 1(NM_021961) \\
\hline & NEUROG3 & 5.51 & 0.0237 & neurogenin 3 (NM_020999) \\
\hline & DYRK1B & 4.48 & 0.239 & $\begin{array}{l}\text { dual-specificity tyrosine -(Y) phosporylation regulated } \\
\text { kinese 1B (NM_004714) }\end{array}$ \\
\hline & EIE5AL1 & 23.96 & 0.2399 & $\begin{array}{l}\text { eukaryotic translation initiation factor 5A } \\
\text { (NM_001099692) }\end{array}$ \\
\hline \multirow[b]{7}{*}{ Transcription activator activity } & MYOG & 16.54 & 0.0239 & myogenin (mygenic factor 4 ) (NM_002479) \\
\hline & GLI2 & 6.86 & 0.0258 & GLI family zinc finger 28 (NM_005270) \\
\hline & TFE3 & 3.48 & 0.0272 & $\begin{array}{l}\text { transcription factor binding to IGHM enhancer } \\
\text { 3(NM00651) }\end{array}$ \\
\hline & EVXI & 7.82 & 0.0273 & even-skipped homebox 1 (NM_005163) \\
\hline & FOXC1 & 4.44 & 0.0291 & forkhead box C1 (NM_001989) \\
\hline & $\mathrm{HRH} 1$ & 2.91 & 0.0303 & histamine receptor H1 (NM_001098213) \\
\hline & AKT1 & 4.76 & 0.0303 & $\begin{array}{l}\text { v-akt murine thymoma viral oncogene homolog } 1 \\
\text { (NM_005163) }\end{array}$ \\
\hline \multirow[t]{8}{*}{$\begin{array}{l}\text { pvalue : } 5.7 \times 10^{-4} \\
\text { FDR: } 7.1 \times 10^{-2}\end{array}$} & CTRC1 & 7.89 & 0.3311 & $\begin{array}{l}\text { CREB regulated transcription coactivator } 1 \\
\left(\mathrm{NM} \_001098482\right)\end{array}$ \\
\hline & CARD11 & 7.10 & 0.0318 & $\begin{array}{l}\text { caspase recruitement domain family, member } 11 \\
\text { (AK097139) }\end{array}$ \\
\hline & CD80 & 3.53 & 0.0335 & CD80 molecule RG Homo sapiens (NM_001042454) \\
\hline & IL17F & 4.13 & 0.0351 & interleukin 17F (NM_021784) \\
\hline & RARG & 7.08 & 0.369 & retinoic acid receptor, gamma (NM_000966) \\
\hline & TGTBI111 & 4.38 & 0.0369 & transforming growth factor beta \\
\hline & FOXA2 & 2.89 & 0.0411 & forkhead box A2 (NM_021784) \\
\hline & BHLHE23 & 5.27 & 0.0420 & basic helix-loop-helix-family, member e23 (NM_080606) \\
\hline \multirow{7}{*}{ Structural molecule activity } & SPTBN2 & 3.36 & 0.0084 & spectrin, beta, non-erythocytic 2 (NM_006946) \\
\hline & AGRN & 5.02 & 0.0088 & agrin (NM_198576) \\
\hline & CLDN19 & 3.82 & 0.0094 & claudin 19 (NM_001123395) \\
\hline & KRT8 & 3.48 & 0.0102 & keratin 8 (NM_002273) \\
\hline & COL5A1 & 6.53 & 0.0142 & collagen, type V, alpha 1 (NM_000093) \\
\hline & KRTAP1 & 3.54 & 0.00170 & keratin associated protein 1-3 (NM_030966) \\
\hline & KRT7 & 8.75 & 0.0179 & keratin 7 (NM_005556) \\
\hline
\end{tabular}




\begin{tabular}{lllll}
\hline & EMILIN1 & 3.04 & 0.0186 & elastin mocrofibril interfacer 1 (NM_007046) \\
\cline { 2 - 5 } & COL27A1 & 6.30 & 0.0204 & collagen, type XXVII, alpha 1 (NM 032888) \\
\cline { 2 - 5 } MUC6 & 4.66 & 0.0271 & mucin 6 (NM_005961) \\
\hline KRT1 & 6.10 & 0.0307 & keratin 1 (NM_006121) \\
\hline KRT73 & 5.67 & 0.0307 & lamin A/C (NM_170707) \\
\hline MUC3B & 4.89 & 0.0311 & mucin 3B, cell surface associated (ENST00000379458) \\
\hline COL11A2 & 8.72 & 0.0369 & collagen, type XI, alpha 2 (NM_001163771) \\
\hline EVPL & 4.72 & 0.0401 & evoplakin (NM_170707) \\
\hline KRT81 & 5.89 & 0.425 & keratin 81 (NM_002281) \\
\hline CHAD & 3.72 & 0.0473 & chondroadherin (NM_001267) \\
\hline LAMC3 & 4.26 & 0.0473 & laminin, gamma 3 (NM_006059) \\
\hline
\end{tabular}

Gene ontology was performed using the Database for Annotation, Visualization and Integrated Discovery (DAVID). For this analysis, biological processes associated to each transcript were used to establish significant functional categories among the top results in each family. Ontology results from the DR (2) and Q families (2) are shown.

of 23 transcripts (including those of 6 keratin genes, 4 collagen genes and 2 laminin genes) although pvalue and FDR score of this cluster do not reach statistical significance.

On the other hand, when compared either with asymptomatic or control individuals, severely affected members of the $\mathrm{Q}$ family exhibit an expression pattern characterized by the upregulation of 43 genes which take part in diverse biological processes. Nevertheless, no significant functional cluster could be detected.

\section{Family $A R$}

Most of the members carrying the R472X substitution in this family (AR0, AR2, AR3, AR4, AR5, AR7, AR8, AR9) suffer frequent and mild-to-severe abdominal and/or cutaneous symptoms of HAE. Among them, AR2, AR3 and AR4 are under treatment with attenuated androgens
(Danazol) while their remaining relatives, who experience milder symptoms, do not receive any prophylactic treatment. Only one member of this family, AR10, a 53-year old man, has never manifested clinical signs of HAE nor has been treated for the disease and his diagnosis was achieved only when his affected daughter was studied. No significant disease-modifying factors could be identified in this family.

\section{Discussion}

The aim of the present study was to investigate the influence of the PBMC transcriptome on the predisposition to or protection from developing HAE symptoms. The results presented shed more light on the interface between innate and adaptive immunity in the context of C1-INH deficiency and question the role of local C1-INH synthesis by PBMCs in HAE patients. Effectively, not the
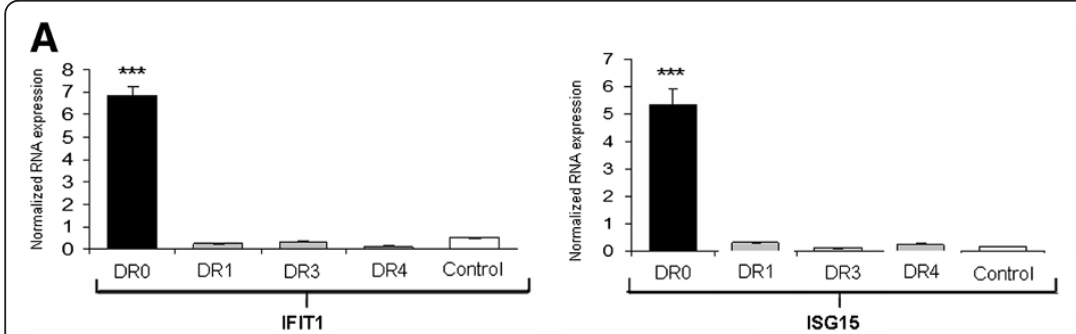

B
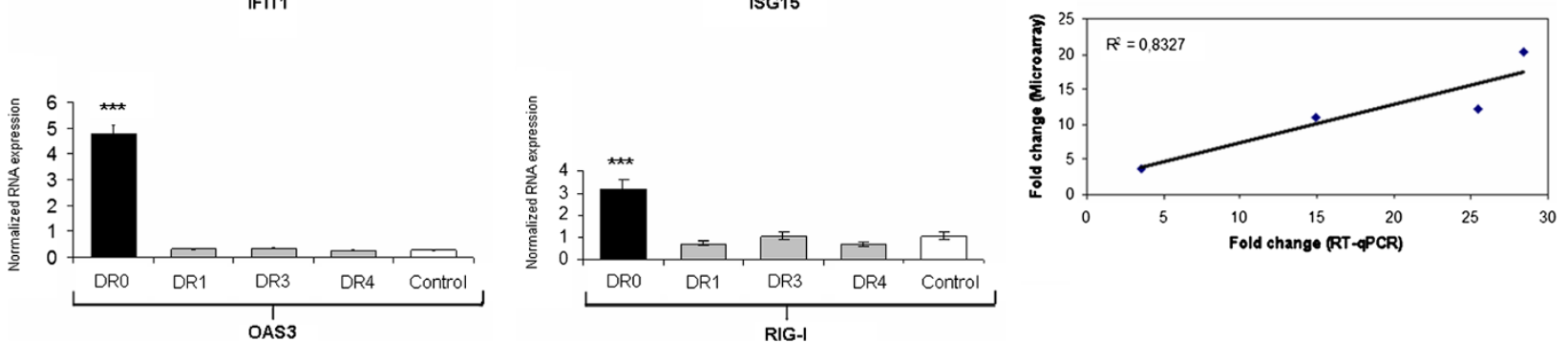

Figure 1 RT-qPCR validation of the microarray results in the DR family. Averaged results of the quantification of IFIT1, ISG15, OAS3 and RIG-I mRNAs from two independent samples are shown A). Correlation between RT-qPCR and microarray results $\mathbf{B})$. The Mann-Whitney statistic was used to verify significant differences among groups. ${ }^{* *}$ denotes pvalue $<0.001$. 

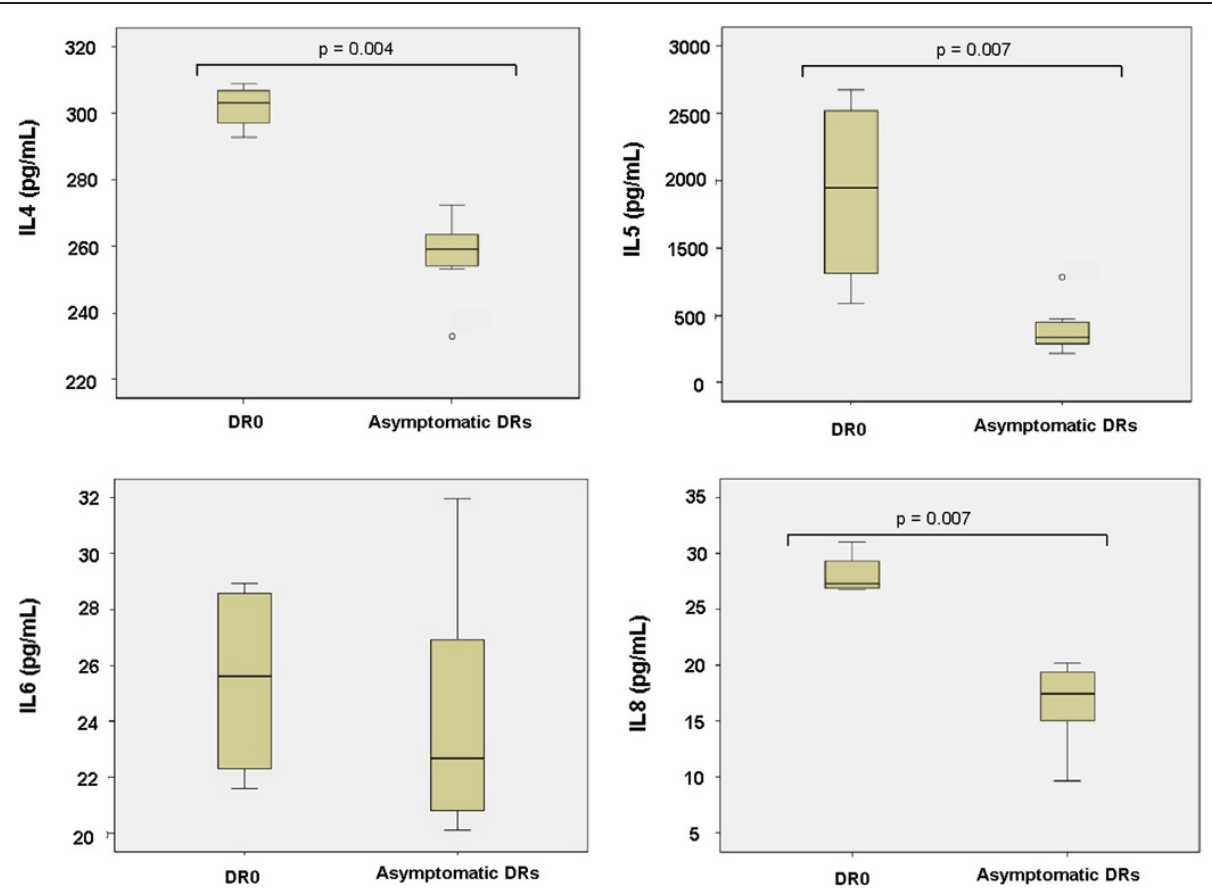

Figure 2 Quantification of cytokines in plasma of the DR family. Measurement was performed with a magnetic-bead-based multiplex immunoassay (Bio-Rad). Averaged results from two independent samples are shown. The medium bar in the box and whisker plots corresponds to the median from two independent samples. In both assays, plasma from patient DRO had significantly higher concentrations of IL4, IL5 and IL8 than control plasmas and asymptomatic patients. IL6 was also higher in DRO, although it did not reached significance. Statistical analyses were performed with the Mann-Whitney test.

PBMCs synthesis of C1-INH mRNA, nor that of other molecules classically implicated in the pathogenesis of HAE like Angiotensin Converting Enzyme (ACE), Bradykinin Receptors 1 and 2, (BDKR1, BDKR2) or Aminopeptidase P (APP) showed any statistical effect on the frequency of HAE attacks $[18,19]$. In agreement with that, instead of a common disease-associated signature, PBMCs from the three families analyzed exhibit different expression patterns linked to their symptoms. What is more, the most significant results in the present work were obtained in the symptomatic individual from the DR family, whose expression profile strongly suggests host response to viral infection as the major diseaseprecipitating factor. This facts might indicate that local protein synthesis by the PBMC milieu plays only a modest role under the circumstances analyzed here (in a free-of-symptoms period).

This interpretation of the results differs from reports by Klausegger et al. describing a child affected of Evans syndrome and HAE, whose angioedema symptoms were clinically and biochemically cured by stem cell bone marrow transplantation [20]. Although the authors report a complete cure of HAE signs which is supported by the rising in serum C1-Inh function from $5-50 \%$ to $84 \%$ of control values, circulating levels of $\mathrm{C} 4$ in the patient are still at the lower limit of normality two years after transplantation $(11.2 \mathrm{mg} / \mathrm{dL})$. Besides, he is still in his childhood years, and given that HAE tends to manifest or worsen at puberty, a longer follow-up period would be recommendable to confidently assess full recovery of normal C1-Inh synthesis. On the other hand, the apparent discrepancy between the case reported by Klausegger et al. and the results presented here could in fact reflect a lack of statistical power in our experimental design, either by the reduced sample size or due to the small effect of the investigated disease-modifiers in the PBMCs. In that case, a more robust design of the study (e.g. RNA analysis of patients in the course of an attack versus asymptomatic patients) might overcome the statistical difficulties. Alternatively, the interrogation of a different tissue -like biopsy derived endothelial cell or hepatocyte cultures- could be a more appropriate experimental setting, although the difficulty of obtaining an adequate sample size from patients' biopsies is evident. In the case of the present study, samples from different tissues were initially considered, but PBMCs were chosen as the most affordable option.

Regarding the results obtained in the DR family, we measured RNA expression of upregulated genes ISG15, IFIT1, OAS3 and RIG-I by RT-qPCR with TaqMan primers and probes. In all cases, the results of microarray and RT-qPCR experiments correlated adequately, for an 
overall correlation coefficient of $\mathrm{R}^{2}: 0.8327$ (Figure 1). We did not validate the microarray results at the protein level due to the lack of a convenient commercial kit, but we did intend to characterize the cytokine profile in the sera from the DR family members with a magnetic-bead-based multiplex immunoassay. The results from two independent samples demonstrated higher serum levels of IL4 (pvalue:0.004), IL5 (pvalue:0.007) and IL8 (pvalue:0.007) in the symptomatic patient DR0 as compared to both healthy controls and asymptomatic DRs. Given that the two samples analyzed were obtained within a 10 months interval and based on the microarray results, this cytokine profile could reflect chronic inflammation or a long-lasting, asymptomatic infection in the patient.

The role for adaptive immunity in the development of HAE has remained controversial along the years. HAE symptomatology is accompanied by a higher prevalence of autoimmunity including glomerulonephritis, lupus-like disorders and Sjögren's syndrome [21]. In the context of a C1-INH deficiency, abnormal activation of complement via the classical pathway consumes the initial components of the cascade and may expose HAE patients to an increased risk of immune-complex disease, as seen in the $\mathrm{C} 2$ or $\mathrm{C} 4$ deficiencies.

Several reports exist that describe immunoregulatory alterations in HAE ranging from autoimmunity (glomerulonephritis and Sjögren's syndrome being the most frequent conditions) to unbalanced $\mathrm{T}$ cell subpopulations or polyclonal B cell activation [22]. However, while some recent publications in the field found a higher prevalence of autoimmune disorders but failed to detect further immunoregulatory defects [23], others have shown abnormalities in the biology of HAE memory B cells that provide a rationale for the high prevalence of autoimmunity observed in this disease [24]. The latter include higher overall phosphotyrosine levels and enhanced expression of CD69, CD5, CD21 and Toll-Like Receptor 9 (TLR-9) in memory B cells of HAE patients as compared to controls. What is more, Kessel and colleagues demonstrated that TLR-9 expression was higher in the memory B cells of those HAE cases where autoantibodies were also present, suggesting that the enhanced production of autoantibodies in this disorder is most probably due to increased B cell activation.

The implication and importance of adaptive immunity in the development of HAE is also supported by clinical observations in series of patients. Cedzyński and colleagues analyzed the effect of infectious disease on the clinical scores for the frequency and severity of HAE symptoms. Their results, although not reaching significance, showed that infection by Helicobacter pylori and Hepatitis B virus may slightly worsen HAE pathology [25]. Infection by $H$. pylori has also been reported to cause acquired C1-INH deficiency in a case report by Farkas and colleagues. The authors attributed this effect to the excessive consumption of complement by antibodies directed against H. pylori. Moreover, successful eradication of the pathogen in the patient resulted in a fivefold reduction in- or complete disappearance of HAE symptoms [26]. Thus, it is predictable that infectious diseases resulting in enhanced antibody response and the formation of immune complexes may trigger the overuse of already reduced C1-INH in HAE patients [27].

In contrast to the DR family, symptomatic members from the $\mathrm{Q}$ family show no evidence of viral infection as a noteworthy precipitating factor. Instead, the transcriptome signature observed in these individuals is more complex and consists of 43 genes upregulated in the severely affected Q members versus 394 transcripts showing higher expression in their symptom-free relatives. Given the high number of genes with altered expression in this family and their diverse clustering options, it is difficult to give a simple interpretation to the results. As shown in Table 2, gene ontology analysis renders only one significant cluster of genes associated to transcription activator activity.

Regarding the AR family, where no significant hit was detected, it is likely that the high proportion of ARs receiving androgen prophylactic treatment at the time of sampling (5 out of 8 patients) would wipe away the individual differences of gene expression and explain the lack of overall results in the family.

The present results arise from the study of a very reduced number of HAE families harbouring the same HAE type I mutation. It is likely that part of the expression profiles characterized in this cohort represent only patient- and/or mutation-specific signatures, rather than general mechanisms of the disease.

All considered, our data did not provide new major evidences concerning the role of PBMCs in the development of HAE in basal, out of crises, situations. The strong association between asymptomatic viral infection and HAE severity observed in the DR family supports the idea of infectious diseases as a major precipitating factor, which is endorsed by abundant clinical observations [6,24]. However, data from a single family cannot be extrapolated further and large scale, systematic screening studies would be needed to statistically associate the mRNA expression pattern observed in the DR0 patient with predisposition to HAE flares.

\section{Additional files}

Additional file 1: Table S1. DR family. Genes upregulated in Asymptomatic versus Control individuals.

Additional file 2: Table S2. DR family. Genes upregulated Symptomatic versus Control individuals.

Additional file 3: Table S3. Q family. Genes upregulated in Asymptomatic versus Control individuals. 


\section{Abbreviations}

HAE: Hereditary angioedema; C1-INH: C1 Inhibitor protein; C1INH: C1 Inhibitor gene; FXII: Coagulation factor XII; PBMCs: Peripheral blood mononuclear cells; FC: Fold change; FDR: False discovery rate.

\section{Competing interest}

The authors declare that they have no competing interests.

\section{Authors' contributions}

ALL analyzed microarray data, performed the validation of the results and wrote the manuscript. FSC carried out hybridization and microarray procedures. SG took prepared the biological samples and took part in the validation of the results. AD participated in the experimental design and provided valuable advice for the analyses of the results. MLT planned the study and took part in the interpretation of the results and writing of the manuscript. All authors read and approved the manuscript.

\section{Acknowledgements}

We are grateful to Drs. Carmen Marcos Bravo (Sección de Alergología, Hospital Meixoeiro, Vigo, Pontevedra), Teresa González Quevedo (Servicio de Alergia, Hospital Universitario Virgen del Rocío, Sevilla) and Raquel López (Servicio de Alergia, Centro Hospitalario Arquitecto Marcide, Ferrol, La Coruña) for sending us the patients. We also thank Miguel Calero and his lab members, from Centro Nacional de Microbiología at Instituto de Salud Carlos III (Majadahonda, Madrid). Last but not least, we are thankful to the patients and their families who made this work possible.

\section{Funding}

This work has been supported by Centro Investigación Biomédica en Red de Enfermedades Raras, CIBERER (INTRA/09/758,2) and Ministerio de Ciencia e Innovación PI09/00122 and a grant by the Autonomous Region of Madrid (S2010/BMD-2316)

\section{Author details}

${ }^{1}$ Immunology Unit, Hospital Universitario La Paz and Hospital La Paz Research Institute (IdiPAZ), Madrid, Spain. ${ }^{2}$ Centre for Biomedical Network Research on Rare Diseases (CIBERER), Instituto de Salud Carlos III (ISCIII), Madrid, Spain. ${ }^{3}$ Genomics Unit, Centro Nacional de Investigaciones Cardiovasculares, (CNIC), Madrid, Spain.

\section{Received: 15 March 2013 Accepted: 9 May 2013}

Published: 20 May 2013

\section{References}

1. Caballero T, Baeza ML, Cabañas R, Campos A, Cimbollek S, Gómez-Traseira C, González-Quevedo T, Guilarte M, Jurado-Palomo J, Larco Jl, López-Serrano MC, López-Trascasa M, Marcos C, Muñoz-Caro JM, Pedrosa M, Prior N, Rubio M, Sala-Cunill A, Spanish Study Group on Bradykinin-Induced Angioedema (SGBA): Consensus statement on the diagnosis, management, and treatment of angioedema mediated by bradykinin. Part I. Classification, epidemiology, pathophysiology, genetics, clinical symptoms, and diagnosis. J Investig Allergol Clin Immunol 2011, 21(5):333-347.

2. Cichon S, Martin L, Hennies HC, Müller F, Van Driessche K, Karpushova A Stevens W, Colombo R, Renné T, Drouet C, Bork K, Nöthen MM: Increased activity of coagulation factor XII (Hageman factor) causes hereditary angioedema type III. Am J Hum Genet 2006, 79(6):1098-1104.

3. Bossi F, Peerschke El, Ghebrehiwet B, Tedesco F: Cross-talk between the complement and the kinin system in vascular permeability. Immunol Lett 2011, 140(1-2):7-13.

4. Joseph K, Tuscano TB, Kaplan AP: Studies of the mechanisms of bradykinin generation in hereditary angioedema plasma. Ann Allergy Asthma Immunol 2008, 101(3):279-286.

5. Nussberger J, Cugno M, Amstutz C, Cicardi M, Pellacani A, Agostoni A: Plasma bradykinin in angio-oedema. Lancet 1998, 351(9117):1693-1697.

6. Agostoni A, Aygören-Pürsün E, Binkley KE, Blanch A, Bork K, Bouillet $L$, Bucher C, Castaldo AJ, Cicardi M, Davis AE, De Carolis C, Drouet C, Duponchel C, Farkas H, Fáy K, Fekete B, Fischer B, Fontana L, Füst G, Giacomelli R, Gröner A, Hack CE, Harmat G, Jakenfelds J, Juers M, Kalmár L, Kaposi PN, Karádi I, Kitzinger A, Kollár T, Kreuz W, Lakatos P, Longhurst HJ, Lopez-Trascasa M, Martinez-Saguer I, Monnier N, Nagy I, Németh E, Nielsen EW, Nuijens JH, O'grady C, Pappalardo E, Penna V, Perricone C, Perricone R,
Rauch U, Roche O, Rusicke E, Späth PJ, Szendei G, Takács E, Tordai A, Truedsson L, Varga L, Visy B, Williams K, Zanichelli A, Zingale L: Hereditary and acquired angioedema: problems and progress: proceedings of the third C1 esterase inhibitor deficiency workshop and beyond. J Allergy Clin Immunol 2004, 114(3 Suppl):S51-S131.

7. Cillari E, Misiano G, Aricò M, La Rocca E, Lio D, di Leonardo S, Brai M: Modification of peripheral blood T-lymphocyte surface receptors and Langerhans cell numbers in hereditary angioedema. Am J Clin Pathol 1986, 85(3):305-311.

8. Brickman CM, Tsokos GC, Chused TM, Balow JE, Lawley TJ, Santaella M, Hammer CH, Linton GF, Frank MM: Immunoregulatory disorders associated with hereditary angioedema. II. Serologic and cellular abnormalities. J Allergy Clin Immunol 1986, 77(5):758-767.

9. Gelfand JA, Sherins RJ, Alling DW, Frank MM: Treatment of hereditary angioedema with danazol. Reversal of clinical and biochemical abnormalities. N Engl J Med 1976, 295(26):1444-1448.

10. Bolstad BM, Irizarry RA, Astrand M, Speed TP: A comparison of normalization methods for high density oligonucleotide array data based on variance and bias. Bioinformatics 2003, 19(2):185-193.

11. Vasekar M, Craig TJ: ACE inhibitor-induced angioedema. Curr Allergy Asthma Rep 2012, 12(1):72-78.

12. Kato H, Takeuchi $O$, Sato S, Yoneyama M, Yamamoto M, Matsui K, Uematsu S, Jung A, Kawai T, Ishii K, Yamaguchi O, Otsu K, Tsujimura T, Koh CS, Reise Sousa C, Matsuura Y, Fujita T, Akira S: Differential roles of MDA5 and RIG-I helicases in the recognition of RNA viruses. Nature 2006, 441(7089):101-105.

13. Co JG, Witwer KW, Gama L, Zink MC, Clements JE: Induction of innate immune responses by SIV in vivo and in vitro: differential expression and function of RIG-I and MDA5. J Infect Dis 2011, 204(7):1104-1114.

14. Greenfeder S, Umland SP, Cuss FM, Chapman RW, Egan RW: Th2 cytokines and asthma. The role of interleukin-5 in allergic eosinophilic disease. Respir Res 2001, 2(2):71-79. Review.

15. Mukaida N: Pathophysiological roles of interleukin-8/CXCL8 in pulmonary diseases. Am J Physiol Lung Cell Mol Physiol 2003, 284(4):L566-L577. Review.

16. Li H, Richardson WD: The evolution of Olig genes and their roles in myelination. Neuron Glia Biol 2008, 4(2):129-135

17. Spellman R, Rideau A, Matlin A, Gooding C, Robinson F, McGlincy N, Grellscheid SN, Southby J, Wollerton M, Smith CW: Regulation of alternative splicing by PTB and associated factors. Biochem Soc Trans 2005, 33(Pt 3):457-460.

18. Freiberger $T$, Grombiríková H, Ravčuková B, Jarkovský J, Kuklínek P, Kryštůfková O, Hanzlíková J, Daňková E, Kopecký O, Zachová R, Lahodná M, Vašáková M, Grodecká L, Litzman J: No evidence for linkage between the hereditary angiooedema clinical phenotype and the BDKR1, BDKR2, ACE or MBL2 gene. Scand J Immunol 2011, 74(1):100-106.

19. Duan QL, Nikpoor B, Dube MP, Molinaro G, Meijer IA, Dion P, Rochefort D, Saint-Onge J, Flury L, Brown NJ, Gainer JV, Rouleau JL, Agostoni A, Cugno M, Simon P, Clavel P, Potier J, Wehbe B, Benarbia S, Marc-Aurele J, Chanard J, Foroud T, Adam A, Rouleau GA: A variant in XPNPEP2 is associated with angioedema induced by angiotensin l-converting enzyme inhibitors. Am J Hum Genet 2005, 77(4):617-626.

20. Klausegger A, Wiednig M, Urban C, Lackner H, Reiter $H$, Bauer JW, Aberer W: Successful allogeneic cord blood transplantation in a patient with Evans syndrome leads to correction of hereditary angioedema type I as secondary effect. Bone Marrow Transplant 2012, 47(9):1259-1261

21. Brickman CM, Tsokos GC, Balow JE, Lawley TJ, Santaella M, Hammer CH, Frank MM: Immunoregulatory disorders associated with hereditary angioedema. I. Clinical manifestations of autoimmune disease. J Allergy Clin Immunol 1986, 77(5):749-757

22. Farkas H, Csuka D, Gács J, Czaller I, Zotter Z, Füst G, Varga L, Gergely P: Lack of increased prevalence of immunoregulatory disorders in hereditary angioedema due to C1-inhibitor deficiency. Clin Immunol 2011, 141(1):58-66. Epub 2011.

23. Kessel A, Peri R, Perricone R, Guarino MD, Vadasz Z, Novak R, Haj T, Kivity S, Toubi E: The autoreactivity of B cells in hereditary angioedema due to C1 inhibitor deficiency. Clin Exp Immunol 2012, 167(3):422-428.

24. Cedzyński M, Madaliński K, Gregorek H, Swierzko AS, Nowicka E, Obtułowicz K, Dzierzanowska-Fangrat K, Wojda U, Rabczenko D, Kawakami M: Possible disease-modifying factors: the mannan-binding lectin pathway and infections in hereditary angioedema of children and adults. Arch Immunol Ther Exp (Warsz) 2008, 56(1):69-75. 
25. Farkas $\mathrm{H}$, Gyeney L, Majthényi P, Füst G, Varga L: Angioedema due to acquired C1-esterase inhibitor deficiency in a patient with Helicobacter pylori infection. Z Gastroenterol 1999, 37(6):513-518.

26. Farkas H, Füst G, Fekete B, Karádi I, Varga L: Eradication of Helicobacter pylori and improvement of hereditary angioneurotic oedema. Lancet 2001, 358(9294):1695-1696.

27. Frank MM, Gelfand JA, Atkinson JP: Hereditary angioedema: the clinical syndrome and its management. Ann Intern Med 1976, 84(5):580-593.

doi:10.1186/1750-1172-8-77

Cite this article as: López-Lera et al:: Disease-modifying factors in

hereditary angioedema: an RNA expression-based screening. Orphanet

Journal of Rare Diseases 2013 8:77.

\section{Submit your next manuscript to BioMed Central and take full advantage of:}

- Convenient online submission

- Thorough peer review

- No space constraints or color figure charges

- Immediate publication on acceptance

- Inclusion in PubMed, CAS, Scopus and Google Scholar

- Research which is freely available for redistribution 